\title{
Relationship of quadriceps muscle power and optimal shortening velocity with angiotensin- converting enzyme activity in older women
}

This article was published in the following Dove Press journal:

Clinical Interventions in Aging

19 October 2017

Number of times this article has been viewed

\author{
Joanna Kostka ${ }^{1,2}$ \\ Joanna Sikora ${ }^{3}$ \\ Tomasz Kostka'
}

'Department of Geriatrics, Healthy Ageing Research Centre, ${ }^{2}$ Department of Physical Medicine, ${ }^{3}$ Laboratory of Bioanalysis, Department of Pharmaceutical Chemistry, Drug Analysis and Radiopharmacy, Medical University of Lodz, Lodz, Poland
Correspondence: Joanna Kostka Department of Physical Medicine, Medical University of Lodz, Plac Hallera I, 90-647 Lodz, Poland

Tel/fax +48 426793 I 44 int 25 I

Email joanna.kostka@umed.lodz.pl
Background: The goal of this study was to assess whether angiotensin-converting enzyme (ACE) activity is related to muscle function (strength, power and velocity), as well as to assess if ACE inhibitors (ACEIs) and other angiotensin system blocking medications (ASBMs) influence muscle performance in elderly women.

Subjects and methods: Ninety-five community-dwelling elderly women took part in this study. Anthropometric data, blood ACE activity analysis, maximum power $\left(\mathrm{P}_{\max }\right)$ and optimal shortening velocity $\left(v_{\text {opt }}\right)$ of the knee extensor muscles, handgrip strength, physical activity (PA) and functional performance were measured.

Results: Women taking ACEI were on average almost 2 years older than the women who did not take ACEI. They took more medicines and were also characterized by significantly lower level of ACE, but they did not differ in terms of PA level, results of functional performance and parameters characterizing muscle functions. No correlations of ACE activity with $\mathrm{P}_{\max }$ and handgrip strength, as well as with PA or functional performance were found. Higher ACE activity was connected with lower $v_{\text {opt }}$ for women who did not take any ASBMs (rho $=-0.37 ; p=0.01$ ).

Conclusion: Serum ACE activity was not associated with muscle strength, power and functional performance in both ASBM users and nonusers, but was associated with optimal shortening velocity of quadriceps muscles in older women. Further prospective studies are needed to assess if ACEIs or other ASBMs may slow down the decline in muscle function and performance.

Keywords: sarcopenia, frailty, muscle strength, functional performance, aging, ACE inhibitors

\section{Introduction}

Preservation of muscle mass and function is one of the most important factors determining the functional performance in the elderly. The phenomenon of age-related sarcopenia is associated with an increased risk of frailty development, hospitalization, disability and death. ${ }^{1}$

Despite strong evidence that properly programmed physical activity (PA) is the most effective way to maintain or even increase muscle mass and strength, ${ }^{2,3}$ many seniors remain inactive and do not follow the American College of Sports Medicine recommendations on PA. ${ }^{4}$ That is why alternative methods to inhibit muscle mass loss with aging are being sought. ${ }^{2}$ There is some evidence that lower angiotensin-converting enzyme (ACE) activity is connected with type II genotype or taking ACE inhibitors (ACEIs) can affect the function of the muscles. ${ }^{5}$ The results of some studies suggest that lower ACE activity has a favorable effect on the cross section of type I fibers responsible for endurance capacity. Combination of ACEI and exercise promotes an increase in the percentage of type I fibers in rats, ${ }^{6}$ whereas endurance athletes more 
often have the $A C E$ II genotype connected with lower ACE activity $^{7}$ and treatment with ACEI results in a shift from type II to type I muscle fibers in patients with congestive heart failure. ${ }^{8}$ Age-related muscle changes have a greater effect on type II fibers and, as a result, on muscle strength and power. ${ }^{9}$ The data on the effect of ACEIs on muscle strength are inconclusive. A 3-year observational study (elderly women with hypertension and without congestive heart failure) has shown that ACEI treatment may slow age-related decline in muscle strength. ${ }^{10}$ On the other hand, in Witham et al's ${ }^{11}$ study, ACEI treatment was not associated with slower decline in handgrip strength during a follow-up period of 4.4 years in healthy seniors.

Decline in muscle power (force and velocity indicator) with aging is larger than the drop in muscle strength. ${ }^{12}$ It is also known that muscle power and velocity are better predictors of functional performance of seniors than strength. ${ }^{13,14}$ There is a deficit of studies assessing the relationship of ACE activity as well as ACEI therapy with muscle power and velocity in elderly people. Therefore, the goal of our study is to assess whether ACE activity affects muscle function (strength, power and velocity), as well as to assess if ACEI and other angiotensin system blocking medications (ASBMs) influence muscle performance in elderly women.

\section{Subjects and methods Subjects}

The study was performed in community-dwelling older women recruited through local media ( $\mathrm{TV}$, radio and newspapers) in the University Department of Geriatrics. Due to safety reasons, patients with recent ( $<3$ months) diagnosis of myocardial infarction, stroke or orthopedic surgery were not allowed to participate in the study. Furthermore, patients with cardiac contraindications to exercise tests or who were unable to perform tests due to motor system dysfunctions (limited range of motion, pain) were excluded from the study. Inclusion criteria were age $\geq 60$ years, female gender, ability to understand and execute commands, ability to perform exercise tests and willing to give written consent to participate in the study. Out of 100 women consecutively recruited within a year, 95 women met the inclusion criteria and participated in the study. The study was approved by the Bioethics Committee of the Medical University of Lodz, and written informed consent was obtained from all subjects.

\section{Protocol}

The subjects were asked to report to the research center between 8:00 and 9:00 am after overnight fasting for a minimum of 12 hours, overnight rest and restraining from physical exercises, smoking and alcohol for at least 12 hours before laboratory measurements. After drawing fasting blood, all the participants were given a light breakfast, and a multidimensional assessment was performed with each subject. During the interview, information on socioeconomic status, habitual PA, current and previous illnesses and current medication was obtained.

\section{Anthropometric data}

Anthropometric data were collected by standard methods. Height and weight were measured and the body mass index $\left(\mathrm{kg} \mathrm{m}^{-2}\right)$ was calculated. Skinfold measurements were taken at four sites: triceps, biceps, subscapula and supraileum. The percentage of body fat was estimated from skinfold measurements according to Durnin and Womersley. ${ }^{15}$

\section{Physical activity}

PA was assessed using two popular PA questionnaires: the 7-Day Recall PA Questionnaire ${ }^{16}$ and the Stanford Usual Activity Questionnaire. ${ }^{17}$ These questionnaires were chosen because of their high validity demonstrated in older individuals. ${ }^{18}$ Standardized protocols for both questionnaires were used. ${ }^{19}$

The 7-Day Recall PA Questionnaire determines the hours spent sleeping per week, sums up the time spent on light activities (energy expenditure of $1.5 \mathrm{kcal} \mathrm{min}^{-1}$ ), moderate activities (energy expenditure of $4 \mathrm{kcal} \mathrm{min}^{-1}$ ), hard activities (energy expenditure of $6 \mathrm{kcal} \mathrm{min}^{-1}$ ) and very hard activities (energy expenditure of $10 \mathrm{kcal} \mathrm{min}^{-1}$ ) and estimates overall weekly energy expenditure through analysis of PA during the previous 7 days.

The Stanford moderate index allows the assessment of health-related PA behaviors of light and moderate intensities. The respondent indicates the type of behavior typical of his/her exercise habits: climbing the stairs instead of using the elevator, walking instead of driving for a short distance, parking the car further away from the destination in order to approach on foot, walking before or after lunch or dinner, exiting the bus/tram a stop earlier in order to walk the remaining distance or performing other activities of a similar nature. As only two subjects reported any habitual vigorous activities in the Stanford Usual Activity Questionnaire, the Stanford Vigorous Activity Index was not used in this study. The 7-day recall total score (total energy expenditure over past week $\mathrm{kcal} \cdot \mathrm{kg}^{-1} \cdot \mathrm{day}^{-1}$ ) and the Stanford moderate (six habitual activities) index were calculated and used for further comparisons.

\section{Muscle strength}

Handgrip strength was tested using a hydraulic hand dynamometer by Jamar ${ }^{\circledR}$ (Sammons Preston Rolyan, Bolingbrook, 
IL, USA). The dynamometer facilitates measurements of isometric force to $90 \mathrm{~kg}$. According to literature, the measurements are influenced by the subject's position when carrying out the test (lying, sitting or standing). Previous studies have shown better results with a standing position. Therefore, all subjects performed the handgrip strength test in a standing position with shoulder adducted and neutrally rotated and elbow in $90^{\circ}$ flexion with no radioulnar deviation. One-minute rest was given between each attempt, and hands were alternated to minimize fatigue effects. Handgrip strength was measured twice on both sides with pauses between measurements. Better results of the two measurements for each hand were used for the analysis. The results were recorded in kilograms. ${ }^{20}$

\section{Maximum power $\left(\mathrm{P}_{\max }\right)$ and optimal shortening velocity $\left(v_{\text {opt }}\right)$ of the knee extensor muscles}

Mechanical measurements were performed on a frictionloaded cycle ergometer (Monark, type 818E; Stockholm, Sweden). This methodology has previously been described and validated in a population of older adults. ${ }^{21}$ The ergometer was instrumented with a strain gauge (KMM20 type, 200 N; WObit, Poznań, Poland) and an incremental encoder (Rotapuls 141-H-200ZCU46L2 type, 200 pts/turn; Lika Electronic, Carre, Italy) for measurement of the frictional force applied by the tension of the belt that surrounded the flywheel and the flywheel displacement, respectively. Instantaneous pedaling velocity $(\mathrm{v})$, force $(\mathrm{F})$ and power output $(\mathrm{P})$ were calculated each $5 \mathrm{~ms}$ and then averaged over each downstroke period. The participants were first familiarized with the ergometer by $5 \mathrm{~min}$ of submaximal cycling and sprints of 3-4 s against different friction loads. After stretching and 5-min rest, the participants were asked to perform two $8 \mathrm{~s}$ sprints from standardized starting position, each separated by at least 5 -min rest. Friction loads were 0.25 and $0.35 \mathrm{~N} \cdot \mathrm{kg}^{-1}$ of the body mass. The $\mathrm{v}-\mathrm{P}$ combinations obtained during two sprints were fitted by a least square mathematical procedure to establish the $\mathrm{v}-\mathrm{P}$ relationship. The highest value of $\mathrm{P}$ (maximal short-term power $-\mathrm{P}_{\max }$ ) and optimal shortening velocity $\left(v_{\text {opt }}-\right.$ velocity at which the power reaches a maximum value) were calculated from a third-order polynomial function. $\mathrm{P}_{\max }$ was expressed relative to body mass $\left(\mathrm{P}_{\max } \cdot \mathrm{kg}^{-1}\left[\mathrm{~W} \cdot \mathrm{kg}^{-1}\right]\right) . v_{\text {opt }}$ was given in number of repetitions per minute $\left(\mathrm{rep} \cdot \mathrm{min}^{-1}\right)$.

\section{Functional performance}

Functional performance was measured using the following tests and scales: Activities of Daily Living scale, ${ }^{22}$ the Lawton
Instrumental Activities of Daily Living scale ${ }^{23}$ and Timed Up and Go test. ${ }^{24}$

Activities of Daily Living scale has six questions concerning basic daily activities: eating, dressing, bathing, continence, toileting and transferring. Lawton Instrumental Activities of Daily Living scale is an instrument to assess independent living skills. It consists of eight questions regarding the following activities: ability to use telephone, shopping, food preparation, housekeeping, laundry, transport, medication use and ability to handle finances. Timed Up and Go test assesses basic functions of daily life: standing up from a standard height chair, walking for a short distance $(3 \mathrm{~m})$, returning and sitting back down as quickly as possible. Time was measured on a stopwatch to the nearest $0.1 \mathrm{~s}$. The patients performed the test twice. The better result was used for the analysis.

\section{Laboratory measurements}

Fasting blood samples for ACE activity analysis were drawn from an antecubital vein into vacuum tubes. Then, serum for analysis was obtained by centrifuging the blood $(2,500 \times g$, $20 \mathrm{~min}, 4^{\circ} \mathrm{C}$ ). Serum was stored at $-20^{\circ} \mathrm{C}$ until the measurements were performed. The ACE activity was measured with commercially available Infinity ${ }^{\mathrm{TM}}$ ACE Assay. Infinity ACE Assay, Infinity ACE calibrators and Infinity ACE controls were obtained from Thermo Scientific ${ }^{\mathrm{TM}}$ (Scoresby, Australia). The Infinity ACE Assay is widely used for monitoring the effects of ACEIs in the treatment of hypertension and heart failure. ACE activity measurement is also used to aid in the differential diagnosis of clinically active pulmonary sarcoidosis and to monitor the effectiveness of steroid therapy. Analyses were carried out with assay protocol on multimode microplate Synergy ${ }^{\mathrm{TM}} \mathrm{H} 1$ reader (Bio-Tek Instruments, Inc., Winooski, VT, USA). In this method, the direct substrate $N$-[3-(2-furyl)-acryloyl]-1-phenyl-alanylglycylglycine is hydrolyzed by serum ACE to N-[3-(2-furyl)-acryloyl]-Lphenyl-alanine and glycylglycine. The hydrolysis of $\mathrm{N}$-[3(2-furyl)-acryloyl]-1-phenyl-alanylglycylglycine by ACE results in a decrease in absorbance at $340 \mathrm{~nm}$. In this method the upper limit of linearity is defined as the activity at which the polynomial regression curve deviates from the straight line of best fit by $5 \%$. The reportable range was determined to be 1 and $120 \mathrm{U} / \mathrm{L}$ of ACE activity. When higher values of ACE activity were detected, serum was appropriately diluted and the measurement was repeated. The reliability of the method was verified with Infinity ACE control plasma: plasma N (24-48 $\mathrm{U} \mathrm{L}^{-1}$ ) and plasma E (53-95 $\left.\mathrm{U} \mathrm{L}^{-1}\right)$, the ACE activity of which amounted to $32.0 \pm 4.5 \mathrm{U} \mathrm{L}^{-1}(\mathrm{n}=5)$ and $70.4 \pm 13.7 \mathrm{U} \mathrm{L}^{-1}(\mathrm{n}=5)$, respectively. 


\section{Statistical analysis}

Data were verified for normality of distribution and equality of variances. The one-way analysis of variance and MannWhitney $U$-test were used to compare the groups. To assess the correlation between quantitative variables, Pearson's and Spearman's correlation coefficients were calculated. The results are presented as the mean $\pm \mathrm{SD}$. The level of significance was set at $p<0.05$ for all the analyses.

\section{Results}

Baseline characteristics of the groups taking or not taking ACEI are shown in Table 1. Women taking ACEI were on average almost 2 years older than those who did not take ACEI; they took more medications and were also characterized by significantly lower level of ACE. Women in both groups did not differ in terms of anthropometric indices, level of education, level of PA, parameters characterizing muscle functions (strength, power, velocity contraction) and results of functional performance (Table 1).

Women taking ACEI more frequently suffered from hypertension $(p<0.001)$, diabetes $(p=0.04)$, ischemic heart disease $(p=0.02)$ and heart failure $(p=0.01)$, which are not shown in the table.

We also analyzed whether taking ASBMs separately (ACEI or angiotensin receptor blockers or antimineralocorticoids) affected muscle function and ACE activity (Table 2). While ACE activity level was the lowest in the ACEI group and the highest in the group of women who did not take any blockers $(p<0.001)$, no differences in muscle function were observed between the groups.

In the entire group of 95 women, no correlations of ACE activity with indicators of muscle function as well as with functional performance measures were found. When we analyzed these relationships separately for ACEI and non-ACEI groups, statistical tendency toward an inverse relationship with $v_{\text {opt }}$ was demonstrated only for non-ACEI group ( $r=-0.23, p=0.06)$.

When we analyzed these relationships in the groups of women who also took other ASBMs (at least one of ACEI, angiotensin receptor blockers, antimineralocorticoids) and in women who did not take them, this association appeared to be stronger ( rho $=-0.37, p=0.01$ ) for women who did not take any ASBMs. Higher ACE activity was associated with lower $v_{\text {opt }}($ Figure 1).

\section{Discussion}

The results of this study show no association between the ACE activity and muscle strength, muscle power as well as functional performance both in the entire group of elderly women and in groups of women taking/not taking ASBMs. On the other hand, some relationship of muscle contraction velocity to ACE levels merits further interest.

Data on the association of ACE with muscle strength and power are most often based on an $A C E$ genotype. ACE activity is associated with genotype (an insertion/deletion polymorphism in the $A C E$ gene). Serum ACE concentration

Table I Baseline characteristics of the study groups

\begin{tabular}{|c|c|c|c|}
\hline Characteristics & $\begin{array}{l}\text { Women taking } \\
\text { ACEI }(n=27)\end{array}$ & $\begin{array}{l}\text { Women not taking } \\
\text { ACEI }(n=68)\end{array}$ & p-value \\
\hline Age (years) & $73.6 \pm 4.7$ & $71.40 \pm 4.2$ & 0.03 \\
\hline Education (years) & $13.8 \pm 3.3$ & $14.5 \pm 2.7$ & 0.50 \\
\hline Medications (number) & $8.1 \pm 4.27$ & $5.2 \pm 3.0$ & 0.002 \\
\hline Body mass $(\mathrm{kg})$ & $69.2 \pm 9.4$ & $68.1 \pm 11.6$ & 0.54 \\
\hline Body mass index $\left(\mathrm{kg} \cdot \mathrm{m}^{-2}\right)$ & $27.5 \pm 3.9$ & $27.1 \pm 4.3$ & 0.47 \\
\hline Fat percentage of body mass (\%) & $37.9 \pm 7.5$ & $37.9 \pm 8.4$ & 0.88 \\
\hline PA energy expenditure (SDRPAQ) $\left(\mathrm{kcal} \cdot \mathrm{kg}^{-1} \cdot \mathrm{day}^{-1}\right)$ & $39.2 \pm 5.6$ & $39.0 \pm 5.0$ & 0.90 \\
\hline PA health-related behaviors (Stanford moderate index) & $1.96 \pm 1.34$ & $2.29 \pm 1.3$ & 0.25 \\
\hline Handgrip strength - left (kg) & $23.6 \pm 8.9$ & $22.8 \pm 7.9$ & 0.67 \\
\hline Handgrip strength - right $(\mathrm{kg})$ & $25.5 \pm 8.2$ & $24.9 \pm 7.8$ & 0.72 \\
\hline$P_{\text {max }}(W)$ & $222 \pm 82$ & $228 \pm 61$ & 0.18 \\
\hline$P_{\max }\left(\mathrm{W} \cdot \mathrm{kg}^{-1}\right)$ & $3.2 \pm 1.2$ & $3.3 \pm 1.0$ & 0.26 \\
\hline$v_{\text {opt }}\left(\right.$ rep $\left.\min ^{-1}\right)$ & $66.3 \pm 11.9$ & $68.8 \pm 9.3$ & 0.29 \\
\hline$A D L$ & $5.80 \pm 0.29$ & $5.83 \pm 0.25$ & 0.62 \\
\hline IADL & $7.96 \pm 0.19$ & $7.97 \pm 0.17$ & 0.85 \\
\hline TUG (s) & $7.4 \pm 1.7$ & $7.2 \pm 2.3$ & 0.27 \\
\hline ACE $\left(U L^{-1}\right)$ & $28.0 \pm 13.3$ & $44.7 \pm 16.3$ & $<0.001$ \\
\hline
\end{tabular}

Note: Data presented as mean \pm standard deviation.

Abbreviations: ACE, angiotensin-converting enzyme; ACEI, ACE inhibitor; ADL, Activities of Daily Living; IADL, Instrumental Activities of Daily Living; PA, physical activity; $P_{\text {max }}$, maximum power; SDRPAQ, 7-Day Recall PA Questionnaire; TUG, Timed Up and Go test; $v_{\text {opt }}$, optimal shortening velocity of the knee extensor muscles. 
Table 2 The influence of ASBMs blockers on muscle function and ACE activity

\begin{tabular}{|c|c|c|c|c|}
\hline \multirow[t]{2}{*}{ Selected characteristics } & \multirow{2}{*}{$\begin{array}{l}\text { Women taking } \\
\text { ACEI }(n=22) \\
\text { Mean } \pm \text { SD }\end{array}$} & \multirow{2}{*}{$\begin{array}{l}\text { Women taking ARBs } \\
\text { or ARBs }+ \text { ACEI }(n=12) \\
\text { Mean } \pm \text { SD }\end{array}$} & \multirow{2}{*}{$\begin{array}{l}\text { Women taking MCRA } \\
\text { or MCRA + ACEI or } \\
\text { MCRA + ARB }(n=10) \\
\text { Mean } \pm \text { SD }\end{array}$} & \multirow{2}{*}{$\begin{array}{l}\text { Women taking } \\
\text { no ASBMs }(n=5 I) \\
\text { Mean } \pm \text { SD }\end{array}$} \\
\hline & & & & \\
\hline Age & $73.6 \pm 4.7$ & $70.8 \pm 4.4$ & $73.1 \pm 3.9$ & $71.5 \pm 4.4$ \\
\hline Hand gripstrength - left (kgf) & $24.2 \pm 9.8$ & $23.3 \pm 7.8$ & $18.1 \pm 5.3$ & $23.5 \pm 7.8$ \\
\hline Handgrip strength - right (kgf) & $25.6 \pm 9.1$ & $24.4 \pm 7.0$ & $22.7 \pm 6.5$ & $25.5 \pm 7.9$ \\
\hline$P_{\max }(W)$ & $217 \pm 88$ & $221 \pm 52$ & $233 \pm 44$ & $230 \pm 65$ \\
\hline$P_{\max }\left(\mathrm{W} \cdot \mathrm{kg}^{-1}\right)$ & $3.1 I \pm 1.20$ & $3.25 \pm 0.88$ & $3.38 \pm 0.95$ & $3.49 \pm 1.05$ \\
\hline$v_{\text {opt }}\left(\right.$ rep $\left.\min ^{-1}\right)$ & $65.2 \pm 11.7$ & $69.6 \pm 8.4$ & $67.0 \pm 13.3$ & $69.2 \pm 9.1$ \\
\hline $\mathrm{ACE}\left(\mathrm{U} \mathrm{L}^{-1}\right)$ & $27.4 \pm 13.4$ & $38.9 \pm 12.9$ & $37.1 \pm 12.3$ & $46.2 \pm 17.5^{\mathrm{a}}$ \\
\hline
\end{tabular}

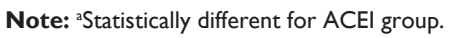

Abbreviations: ACE, angiotensin-converting enzyme; ACEI, ACE inhibitor; ARBs, angiotensin receptor blockers; ASBMs, angiotensin system blocking medications; MCRA, antimineralocorticoid; $P_{\max }$, maximum power; $v_{o p t}$, optimal shortening velocity of the knee extensor muscles.

is higher in people with deletion of allele (DD) than with insertion (II) in $A C E$ gene. ${ }^{25-27}$ Most of the work on this topic concerns the genetic determinants of sports predisposition. It has been suggested that the $\mathrm{D}$ allele determines strength and power, whereas the I allele determines endurance performance and is connected with higher proportion of the type I fibers. ${ }^{28}$ Nevertheless, data on the relationship between $A C E$ genotype or ACE activity and muscle characteristics are ambiguous, particularly in relation to muscle strength and power. In the review report ${ }^{29}$ of 44 studies on $A C E$ gene and human sporting performance, $A C E$ insertion (I) genotype was generally associated with predispositions related to endurance sports; only in one case, in the group of elite Korean power athletes, it was linked with power. ${ }^{30}$ Data on $A C E$ deletion (D) genotype were not so clear in that review. In most cases, this genotype determined power or strength performance; but in almost one-third of the cases, it determined endurance performance. In the 10 studies included in

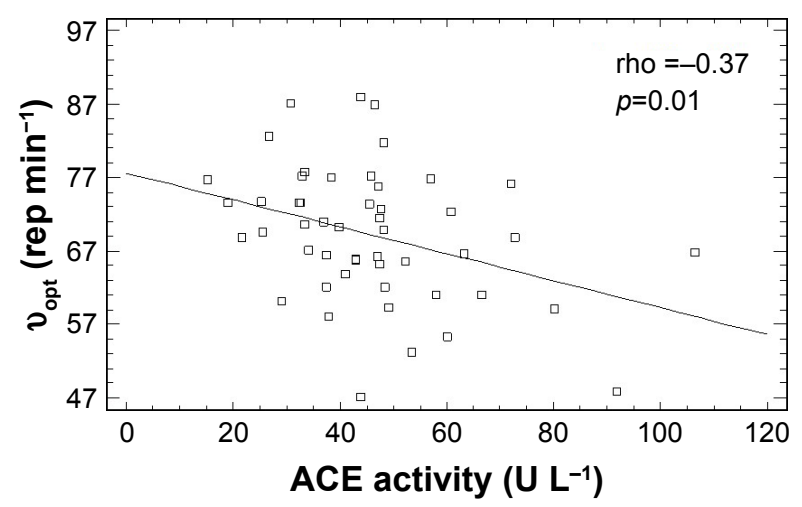

Figure I The relationship between optimal shortening velocity $\left(v_{\text {opt }}\right)$ and ACE activity in women not taking any ASBMs.

Abbreviations: ACE, angiotensin-converting enzyme; ASBMs, angiotensin system blocking medications; $v_{o p t}$, optimal shortening velocity of the knee extensor muscles. the review paper, no link between $A C E$ genotype and sports predisposition was found.

There are also inconclusive data on directly measured serum ACE activity and muscle strength. Williams et $\mathrm{al}^{31}$ reported that the level of ACE activity positively determined both static and dynamic muscle strength in young untrained men, but the changes in muscle strength with training (three times per week, 8 weeks) were independent of the circulating ACE activity. On the other hand, McCauley et $\mathrm{a}^{27}$ reported no association between ACE and knee extension function (including high-velocity strength) in young Caucasian men.

The goal of research on ACE activity has different significance in the elderly than in the young subjects. Aging is associated with a gradual decline in muscle mass and function. This muscle loss refers to type II fibers to a greater extent than to type I fibers. ${ }^{9}$ It is known that fast twitch fibers (type II) determine the muscle strength, power and velocity contraction. ${ }^{32}$ To our knowledge, this is the first study where muscle power and velocity contraction were assessed in relation to ACE activity in elderly women. These two indicators of muscle function have even higher meaning in functional performance than muscle strength, ${ }^{13,14,21}$ and their decline with aging is faster. ${ }^{33}$ Most studies involving muscle strength in the elderly are in line with our results. ACE activity and $A C E$ polymorphism were generally not connected with muscle strength. ${ }^{34-37}$ Kang et al ${ }^{34}$ showed no interrelation between the handgrip strength and the ACE activity (but showed it for muscle fatigability) among older Koreans. Similarly, Bustamante-Ara et $\mathrm{al}^{35}$ reported no association between $A C E$ genotype and handgrip strength as well as leg press strength and functional performance measured with walking speed and step test in nonagenarians. Garatachea et $\mathrm{al}^{36}$ found only weak interrelation between handgrip strength and $A C E$ 
genotype (but without statistical differences after correction for multiple comparisons) and no relationship between $A C E$ genotype with sarcopenia score, muscle quality index as well as functional characteristics. McCauley et $\mathrm{al}^{37}$ did not find any association between $A C E$ insertion/deletion polymorphisms and muscle function, as well as between serum ACE activity and nonskeletal lean mass, whereas serum ACE activity was negatively correlated with high velocity torque of the knee extensors. They also observed negative tendency for the relationship of serum ACE activity with knee extensors isometric strength.

Serum ACE activity is modulated by ACEIs. ${ }^{38}$ They are widely used in the treatment of diseases of the elderly (hypertension, heart failure, ischemic heart disease, diabetes, metabolic syndrome and so on). Therefore, we checked this relationship (ACE activity and muscle function) in the entire group and separately for women treated/not treated with various ASBMs. We observed no relationship between muscle function and serum ACE activity, with the exception of a negative correlation between $v_{\text {opt }}$ and ACE activity in the group of women not taking any of ASBMs.

Muscle shortening velocity was proposed to be one of the most important factors determining functional performance of the elderly, even more than muscle strength or power. ${ }^{14,21}$ It was reported that the renin-angiotensin system hyperactivity may have pathologic effects on skeletal muscles (insulin resistance, atrophy, fibrosis) as well as mitochondrial dysfunction and oxidative stress. ${ }^{39} \mathrm{We}$ did not find the relationship of muscle strength and power with ACE activity, but perhaps $v_{\text {opt }}$ is a more sensitive indicator of muscle function. Moreover, other, for example neuronal mechanisms, may potentially affect velocity of muscle contraction. There is evidence that $A C E$ inhibition may have a neuroprotective effect, ${ }^{40}$ and $A C E$ gene II genotype connected with lower ACE concentration protects against the development of peripheral neuropathy in diabetic patients. ${ }^{41}$ Peroneal motor nerve conduction velocity and $\mathrm{M}$-wave amplitude increased, and the F-wave latency decreased in patients with diabetes after 12 months of treatment with trandolapril (ACEI) compared with placebo. ${ }^{42}$

Interestingly, the results of our observations may also suggest positive effect of ACEI on muscle parameters and functional performance. Women taking ACEI were almost 2 years older, had lower health status manifested by the intake of more drugs and had a higher incidence of diseases, including those that affect muscle quality (diabetes, hypertension, ischemic heart disease and heart failure) ${ }^{43,44}$ Nevertheless, both groups of women did not differ in the handgrip strength, $\mathrm{P}_{\max }, v_{\mathrm{opt}}$ and results of functional performance. These observations are in line with some earlier studies. It was suggested that ACEI treatment may be the pharmacologic option for the treatment of sarcopenia. ${ }^{45}$ Onder et al, ${ }^{10}$ after 3 years of observation of participants with hypertension from the Women's Health and Aging Study, reported lower decline in muscle strength and walking speed in women who took ACEI continuously in comparison with other groups of women (continuous/intermittent users of other antihypertensive drugs or those who never used any antihypertensives). In older adults free of heart failure, ACEI usage was associated with larger lower extremity muscle mass in relation to usage of other drugs ${ }^{46}$ In some studies, the functional effect after ACEI therapy was also observed. In a group of older subjects with mobility problems or functional impairment, improvement in 6-min walking test was reported, ${ }^{5}$ as was the case in patients with left ventricular systolic dysfunction. ${ }^{47}$ ASBM users are also characterized by lower fall risk, but according to some authors, this effect is not directly associated with muscle strength. ${ }^{48}$ On the other hand, Gray et al, ${ }^{49}$ in a prospective study, did not find a relationship between ACEI use and slower decline in muscle strength and physical performance in older women. Similarly, Witham et $\mathrm{al}^{11}$ did not observe effects of ACEI intake on handgrip strength decline in healthy seniors.

\section{Conclusion}

Serum ACE activity is not associated with muscle strength, power and functional performance both in ASBM users and nonusers, but is associated with optimal shortening velocity of quadriceps muscles in older women. Whether ACEI may slow down the decline in muscle function via muscle contraction velocity should be the subject of further prospective research with a larger group of older individuals.

\section{Acknowledgment}

This work was supported by a grant from the Medical University of Lodz no 503/6-077-01/503-61-002.

\section{Disclosure}

The authors report no conflicts of interest in this work.

\section{References}

1. Fielding RA, Vellas B, Evans WJ, et al. Sarcopenia: an undiagnosed condition in older adults. Current consensus definition: prevalence, etiology, and consequences. International working group on sarcopenia. J Am Med Dir Assoc. 2011;12(4):249-256.

2. Burton LA, Sumukadas D. Optimal management of sarcopenia. Clin Interv Aging. 2010;5:217-228. 
3. Papa EV, Dong X, Hassan M. Resistance training for activity limitations in older adults with skeletal muscle function deficits: a systematic review. Clin Interv Aging. 2017;12:955-961.

4. American College of Sports Medicine, Chodzko-Zajko WJ, Proctor DN, Fiatarone Singh MA, et al. American College of Sports Medicine position stand. Exercise and physical activity for older adults. Med Sci Sports Exerc. 2009;41(7):1510-1530.

5. Sumukadas D, Witham MD, Struthers AD, McMurdo ME. Effect of perindopril on physical function in elderly people with functional impairment: a randomized controlled trial. CMAJ. 2007;177(8):867-874.

6. Minami N, Li Y, Guo Q, et al. Effects of angiotensin-converting enzyme inhibitor and exercise training on exercise capacity and skeletal muscle. J Hypertens. 2007;25(6):1241-1248.

7. Gayagay G, Yu B, Hambly B, et al. Elite endurance athletes and the ACE I allele-the role of genes in athletic performance. Hum Genet 1998;103(1):48-50.

8. Vescovo G, Dalla Libera L, Serafini F, et al. Improved exercise tolerance after losartan and enalapril in heart failure: correlation with changes in skeletal muscle myosin heavy chain composition. Circulation. 1998; 98(17):1742-1749.

9. Morley JE. Frailty and Sarcopenia: the New Geriatric Giants. Rev Invest Clin. 2016;68(2):59-67.

10. Onder G, Penninx BW, Balkrishnan R, et al. Relation between use of angiotensin-converting enzyme inhibitors and muscle strength and physical function in older women: an observational study. Lancet. 2002; 359(9310):926-930.

11. Witham MD, Syddall HE, Dennison E, Cooper C, McMurdo ME, Sayer AA. ACE inhibitors, statins and thiazides: no association with change in grip strength among community dwelling older men and women from the Hertfordshire Cohort Study. Age Ageing. 2014;43(5): 661-666.

12. Lauretani F, Russo CR, Bandinelli S, et al. Age-associated changes in skeletal muscles and their effect on mobility: an operational diagnosis of sarcopenia. J Appl Physiol (1985). 2003;95(5):1851-1860.

13. Kostka JS, Czernicki JW, Kostka TJ. Association of muscle strength, power, and optimal shortening velocity with functional abilities of women with chronic osteoarthritis participating in a multi-modal exercise program. J Aging Phys Act. 2014;22(4):564-570.

14. Clémençon M, Hautier CA, Rahmani A, Cornu C, Bonnefoy M. Potential role of optimal velocity as a qualitative factor of physical functional performance in women aged 72 to 96 years. Arch Phys Med Rehabil. 2008;89(8):1594-1599.

15. Durnin JV, Womersley J. Body fat assessed from total body density and its estimation from skinfold thickness: measurements on 481 men and women aged from 16 to 72 years. Br J Nutr. 1974;32(1):77-97.

16. Blair SN, Haskell WL, Ho P, et al. Assessment of habitual physical activity by a seven-day recall in a community survey and controlled experiments. Am J Epidemiol. 1985;122(5):794-804.

17. Sallis JF, Haskell WL, Wood PD, et al. Physical activity assessment methodology in the Five-City Project. Am J Epidemiol. 1985;121(1): 91-106.

18. Bonnefoy M, Normand S, Pachiaudi C, Lacour JR, Laville M, Kostka T. Simultaneous validation of ten physical activity questionnaires in older men: a doubly labeled water study. J Am Geriatr Soc. 2001;49(1): 28-35.

19. Kriska AM, Caspersen CJ. Introduction to a collection of physical activity questionnaires. Med Sci Sports Exerc. 1997;29(Suppl 6): S5-S9.

20. Rantanen T, Guralnik JM, Foley D, et al. Midlife hand grip strength as a predictor of old age disability. JAMA. 1999;281(6):558-560.

21. Kozicka I, Kostka T. Handgrip strength, quadriceps muscle power, and optimal shortening velocity roles in maintaining functional abilities in older adults living in a long-term care home: a 1-year follow-up study. Clin Interv Aging. 2016;26(11):739-747.

22. Katz S, Ford AB, Moskowitz RW, Jackson BA, Jaffe MW. Studies of illness in the aged: the index of ADL, a standardized measure of biological and psychosocial function. JAMA. 1963;185:914-919.
23. Lawton MP, Brody EM. Assessment of older people: self-maintaining and instrumental activities of daily living. Gerontologist. 1969;9(3): 179-186.

24. Podsiadlo D, Richardson S. The timed "up \& go": a test of basic functional mobility for frail elderly persons. J Am Geriatr Soc. 1991;39(2): $142-148$.

25. Rigat B, Hubert C, Alhenc-Gelas F, Cambien F, Corvol P, Soubrier F. An insertion/deletion polymorphism in the angiotensin I-converting enzyme gene accounting for half the variance of serum enzyme levels. J Clin Invest. 1990;86(4):1343-1346.

26. Nakai K, Itoh C, Miura Y, et al. Deletion polymorphism of the angiotensin I-converting enzyme gene is associated with serum ACE concentration and increased risk for CAD in the Japanese. Circulation. 1994;90(5):2199-2202.

27. McCauley T, Mastana SS, Hossack J, Macdonald M, Folland JP. Human angiotensin-converting enzyme I/D and alpha-actinin 3 R577X genotypes and muscle functional and contractile properties. Exp Physiol. 2009;94(1):81-89.

28. Nazarov IB, Woods DR, Montgomery HE, et al. The angiotensin converting enzyme I/D polymorphism in Russian athletes. Eur J Hum Genet. 2001;9(10):797-801.

29. Puthucheary Z, Skipworth JR, Rawal J, Loosemore M, Van Someren K, Montgomery HE. The ACE gene and human performance: 12 years on. Sports Med. 2011;41(6):433-448.

30. Kim CH, Cho JY, Jeon JY, et al. ACE DD genotype is unfavorable to Korean short-term muscle power athletes. Int J Sports Med. 2010;31(1): 65-71

31. Williams AG, Day SH, Folland JP, GohlkeP, Dhamrait S, Montgomery HE. Circulating angiotensin converting enzyme activity is correlated with muscle strength. Med Sci Sports Exerc. 2005;37(6):944-948.

32. Hautier CA, Linossier MT, Belli A, Lacour JR, Arsac LM. Optimal velocity for maximal power production in non-isokinetic cycling is related to muscle fibre type composition. Eur J Appl Physiol Occup Physiol. 1996;74(1-2):114-118

33. Skelton DA, Greig CA, Davies JM, Young A. Strength, power and related functional ability of healthy people aged 65-89 years. Age Ageing. 1994;23(5):371-377.

34. Kang HJ, Kim CH, Park DS, et al. The impacts of ACE activity according to ACE I/D polymorphisms on muscular functions of people aged 65 Ann Rehabil Med. 2012;36(4):433-446.

35. Bustamante-Ara N, Santiago C, Verde Z, et al. ACE and ACTN3 genes and muscle phenotypes in nonagenarians. Int J Sports Med. 2010;31(4): 221-224.

36. Garatachea N, Fiuza-Luces C, Torres-Luque G, et al. Single and combined influence of ACE and ACTN3 genotypes on muscle phenotypes in octogenarians. Eur J Appl Physiol. 2012;112(7):2409-2420.

37. McCauley T, Mastana SS, Folland JP. ACE I/D and ACTN3 R/X polymorphisms and muscle function and muscularity of older Caucasian men. Eur J Appl Physiol. 2010;109(2):269-277.

38. Krasowski MD, Savage J, Ehlers A, et al. Ordering of the serum angiotensin-converting enzyme test in patients receiving angiotensinconverting enzyme inhibitor therapy: an avoidable but common error. Chest. 2015;148(6):1447-1453.

39. Cabello-Verrugio C, Morales MG, Rivera JC, Cabrera D, Simon F. Renin-angiotensin system: an old player with novel functions in skeletal muscle. Med Res Rev. 2015;35(3):437-463.

40. Hanif K, Bid HK, Konwar R. Reinventing the ACE inhibitors: some old and new implications of ACE inhibition. Hypertens Res. 2010;33(1): $11-21$

41. Mansoor Q, Javaid A, Bilal N, Ismail M. Angiotensin-converting enzyme (ACE) gene II genotype protects against the development of diabetic peripheral neuropathy in type 2 diabetes mellitus. J Diabetes. 2012; 4(3):257-261.

42. Malik RA, Williamson S, Abbott C, et al. Effect of angiotensinconverting-enzyme (ACE) inhibitor trandolapril on human diabetic neuropathy: randomised double-blind controlled trial. Lancet. 1998; 352(9145):1978-1981 
43. Park SW, Goodpaster BH, Strotmeyer ES, et al. Decreased muscle strength and quality in older adults with type 2 diabetes: the health, aging, and body composition study. Diabetes. 2006;55(6):1813-1818.

44. Duscha BD, Schulze PC, Robbins JL, Forman DE. Implications of chronic heart failure on peripheral vasculature and skeletal muscle before and after exercise training. Heart Fail Rev. 2008;13(1):21-37.

45. Morley JE. Pharmacologic options for the treatment of sarcopenia. Calcif Tissue Int. 2016;98(4):319-333.

46. Di Bari M, van de Poll-Franse LV, Onder G, et al; Health, Aging and Body Composition Study. Antihypertensive medications and differences in muscle mass in older persons: the Health, Aging and Body Composition Study. J Am Geriatr Soc. 2004;52(6):961-966.
47. Hutcheon SD, Gillespie ND, Crombie IK, Struthers AD, McMurdo ME. Perindopril improves six minute walking distance in older patients with left ventricular systolic dysfunction: a randomised double blind placebo controlled trial. Heart. 2002;88(4):373-377.

48. Wong AK, Lord SR, Sturnieks DL, Delbaere K, Trollor JN, Close JC. Angiotensin system-blocking medications are associated with fewer falls over 12 months in community-dwelling older people. J Am Geriatr Soc. 2013;61(5):776-781.

49. Gray SL, Aragaki AK, LaMonte MJ, et al. Statins, angiotensin-converting enzyme inhibitors, and physical performance in older women. $\mathrm{J} \mathrm{Am}$ Geriatr Soc. 2012;60(12):2206-2214.
Clinical Interventions in Aging

\section{Publish your work in this journal}

Clinical Interventions in Aging is an international, peer-reviewed journal focusing on evidence-based reports on the value or lack thereof of treatments intended to prevent or delay the onset of maladaptive correlates of aging in human beings. This journal is indexed on PubMed Central, MedLine,

\section{Dovepress}

CAS, Scopus and the Elsevier Bibliographic databases. The manuscript management system is completely online and includes a very quick and fair peer-review system, which is all easy to use. Visit http://www.dovepress. com/testimonials.php to read real quotes from published authors. 